\title{
Excessive watering eyes in gastric cancer patients receiving S-1 chemotherapy
}

\author{
Hiroyuki Tabuse $^{1,6} \cdot$ Hiroya Kashiwagi $^{2} \cdot$ Satoshi Hamauchi $^{1} \cdot$ Takahiro Tsushima $^{1}$. \\ Akiko Todaka ${ }^{1} \cdot$ Tomoya Yokota $^{1} \cdot$ Nozomu Machida $^{1} \cdot$ Kentaro Yamazaki $^{1}$. \\ Akira Fukutomi ${ }^{1}$ Y Yusuke Onozawa ${ }^{3} \cdot$ Keita Mori $^{4} \cdot$ Narikazu Boku ${ }^{1,5}$. \\ Masao Ichinose $^{6} \cdot$ Hirofumi Yasui $^{1}$
}

Received: 9 June 2015/Accepted: 26 August 2015/Published online: 11 September 2015

(C) The International Gastric Cancer Association and The Japanese Gastric Cancer Association 2015

\begin{abstract}
Background Watering eyes is a common late adverse event associated with S-1 chemotherapy; however, the frequency and predictive factors are not known.

Methods This study included 304 consecutive gastric cancer patients treated with adjuvant S-1 monotherapy for 1 year at Shizuoka Cancer Center. We retrospectively evaluated the frequency of watering eyes, and explored other nonhematological adverse events during the first course of S-1 monotherapy which could become predictive factors for watering eyes.

Results The severest grade of watering eyes during S-1 monotherapy was grade 2 in 41 patients (13.5\%) and grade 3 in 36 patients $(11.8 \%)$. The median time to onset of grade 2 and grade 3 watering eyes was 82 days (range
\end{abstract}

Hiroyuki Tabuse

h-tabuse@wakayama-med.ac.jp

1 Division of Gastrointestinal Oncology, Shizuoka Cancer Center, 1007 Shimonagakubo, Nagaizumi-cho, Shizuoka 411-8777, Japan

2 Division of Ophthalmology, Shizuoka Cancer Center, 1007 Shimonagakubo, Nagaizumi-cho, Shizuoka 411-8777, Japan

3 Division of Clinical Oncology, Shizuoka Cancer Center, 1007 Shimonagakubo, Nagaizumi-cho, Shizuoka 411-8777, Japan

4 Clinical Trial Coordination Office, Shizuoka Cancer Center, 1007 Shimonagakubo, Nagaizumi-cho, Shizuoka 411-8777, Japan

5 National Cancer Center Hospital, 5-1-1, Tsukiji, Chuo-ku, Tokyo 104-0045, Japan

6 The Second Department of Internal Medicine, Wakayama Medical University, 811-1 Kimiidera, Wakayama City 641-0012, Wakayama, Japan
6-344 days) and 249 days (range 84-653 days), respectively, and the median cumulative S-1 dose at the onset of grade 2 and grade 3 watering eyes was $4174 \mathrm{mg} / \mathrm{m}^{2}$ (range $491-16,095 \mathrm{mg} / \mathrm{m}^{2}$ ) and $10,243 \mathrm{mg} / \mathrm{m}^{2}$ (range $4943-16,341 \mathrm{mg} / \mathrm{m}^{2}$ ), respectively. Multivariate analysis showed that anorexia (odds ratio 2.37, $P=0.008$ ), oral mucositis (odds ratio $3.86, P=0.0003$ ), skin hyperpigmentation (odds ratio 3.84, $P=0.0001$ ), and rash (odds ratio $3.76, P=0.01$ ) observed during the first course were significantly associated with watering eyes.

Conclusion The risk of watering eyes was higher in patients who also had anorexia, oral mucositis, skin hyperpigmentation, or rash during first course of S-1 monotherapy than in those without them.

Keywords Adverse event - Chemotherapy - Gastric cancer $\cdot \mathrm{S}-1 \cdot$ Watering eyes

\section{Introduction}

$\mathrm{S}-1$ is an oral anticancer drug that contains tegafur, gimeracil, and oteracil in a molar ratio of 1:0.4:1 [1]. S-1 plus cisplatin combination therapy has been recognized as a standard treatment for chemonaïve advanced gastric cancer (AGC) patients [2-4], and adjuvant S-1 monotherapy is standard care for patients with stage II and stage III gastric cancer after curative surgery with D2 dissection in Japan [5]. Thus, S-1 is a key, important drug for the treatment of both metastatic and resectable gastric cancer. Recently, S-1 has been used widely to treat various cancers in clinical practice, especially for adjuvant treatment of resected gastric cancer, and watering eyes have come to be recognized as a significant clinical problem that deteriorates the patient's quality of life. 
Thus far, a few studies $[6,7]$ have reported that watering eyes are a common nonhematological adverse event associated with S-1 therapy, along with nausea, diarrhea, oral mucositis, anorexia, dysgeusia, skin hyperpigmentation, and rash. However, previous reports about watering eyes [8-15] have included a small number of patients whose characteristics and chemotherapy regimen differed.

Although watering eyes are considered to be caused by conjunctivitis or dacryostenosis, a type of mucositis, the precise mechanism is not known well. Many physicians do not pay much attention to watering eyes because this disorder is not acute or life-threatening, even though it affects activities of daily living. Exacerbation of this condition could decrease vision, which may deteriorate quality of life. Therefore, the prediction and prevention of watering eyes is very important. However, it has not been established how to identify patients at risk of developing watering eyes.

In this retrospective study, we examined the clinical course of watering eyes and explored predictive factors for gastric cancer patients receiving $\mathrm{S}-1$ monotherapy in an adjuvant setting.

\section{Methods}

\section{Subjects}

This study included 393 AGC patients who received adjuvant S-1 monotherapy between January 2007 and August 2011 at Shizuoka Cancer Center. All patients satisfied the following selection criteria: (1) age 18 years or older; (2) Eastern Cooperative Oncology Group performance status (PS) of 0-2; (3) histologically proven adenocarcinoma; (4) no history of chemotherapy; (5) adequate oral intake; (6) adequate bone marrow, renal, and hepatic function (absolute neutrophil count $1500 / \mu \mathrm{L}$ or greater, platelet count $10,000 / \mu \mathrm{L}$ or greater, serum creatinine level $1.5 \mathrm{mg} / \mathrm{dL}$ or lower, and serum transaminase level $100 \mathrm{IU} /$ L or lower); (7) macroscopically curative resection (R0 and R1) regardless of the cytological findings of abdominal lavage; (8) no synchronous concomitant cancers; and (9) follow-up during the clinical course until completion of S-1 monotherapy at our institution.

Among these patients, 89 were excluded for the following reasons: discontinuation of S-1 monotherapy within 1 year because of recurrence $(n=35)$ or adverse events other than watering eyes $(n=31)$, poor adherence to S-1 therapy for reasons other than adverse events $(n=9)$, onset of other serious diseases during the treatment ( $n=7)$, initiation of S-1 therapy at other hospitals $(n=4)$, transfer to other hospitals during the treatment $(n=2)$, and sudden death from an unknown cause $(n=1)$. Finally, 304 patients were included in this study. We obtained all the clinical data from the medical records retrospectively.

\section{Treatment}

For adjuvant treatment, $\mathrm{S}-1$ at $40 \mathrm{mg} / \mathrm{m}^{2}$ was administered orally twice daily from day 1 to day 28 , followed by a 14-day rest period, and this was repeated for 1 year after curative surgery. The S-1 dose was determined on the basis of body surface area (BSA): $40 \mathrm{mg}$ for BSA less than $1.25 \mathrm{~m}^{2}, 50 \mathrm{mg}$ for BSA between 1.25 and $1.5 \mathrm{~m}^{2}$, and $60 \mathrm{mg}$ for BSA greater than $1.5 \mathrm{~m}^{2}$, twice daily. Dose reduction, delay of the treatment course, and change of the treatment schedule were decided at the discretion of the physician. Generally, physicians considered S-1 dose reduction and/or a schedule modification of the 3-week treatment course (administration for 2 weeks followed by 7 days of rest) if patients experienced any grade 3 or higher hematological adverse events or unacceptable grade 2 or higher nonhematological adverse events other than watering eyes, and if a patient experienced grade 3 watering eyes.

We consulted an ophthalmologist when a patient experienced grade 2 or higher watering eyes. Watering eyes were treated as follows: instillation of artificial tears without preservatives when patients had grade 2 watering eyes, and intervention such as stent insertion for lacrimal drainage if indicated by a periodic water conduction test. Written informed consent for adjuvant chemotherapy was obtained from all patients before the initiation of chemotherapy.

\section{Evaluation of adverse events}

Physical examinations and laboratory tests were repeated every 2 or 3 weeks. Adverse events were evaluated according to the National Cancer Institute Common Terminology Criteria for Adverse Events (CTCAE), version 4.0. Data on adverse events such as anorexia, diarrhea, fatigue, oral mucositis, nausea, skin hyperpigmentation, dysgeusia, and rash were collected retrospectively from the initiation of S-1 monotherapy to 30 days after the completion of the planned eight courses or the last administration of S-1 in patients who discontinued treatment because of watering eyes before eight courses. In daily practice, when grade 2 (requiring medical treatment) or grade 3 (requiring surgical management such as lacrimal drainage) watering eyes were detected by each physician, an ophthalmologist was consulted. For this study, the grade of watering eyes ( 2 or 3 ) was reevaluated by an ophthalmologist because it was difficult to detect and record grade 1 watering eyes (not requiring treatment) retrospectively; grade 4 watering eyes are not defined in the CTCAE. To 
monitor the clinical course of watering eyes with or without treatment, we defined abatement of watering eyes in the case of downgraded severity.

\section{Statistics}

The cumulative incidence of watering eyes was calculated by the Kaplan-Meier method, in which the occurrence of watering eyes was adopted as an event and there were no censored cases in the patients in this study. To explore the risk factors for watering eyes, the relationship between watering eyes and patient background characteristics immediately before the initiation of S-1 monotherapy was investigated with Fisher exact tests. Furthermore, the relationship between nonhematological adverse events during the first course which were significantly associated with the occurrence of watering eyes was investigated both by univariate analysis and by multivariate logistic regression analysis. All tests were two-sided, and $P$ values less than 0.05 were considered significant. All statistical analyses were performed with SPSS version 20 (IBM, Armonk, NY, USA).

This study was approved by the Institutional Review Board of Shizuoka Cancer Center.

\section{Results}

\section{Patient characteristics}

Baseline patient characteristics of the 304 patients in this study are shown in Table 1 . The median age was 67 years (range 30-83 years). The median serum creatinine clearance as calculated by the Cockcroft-Gault equation was $78.2 \mathrm{~mL} / \mathrm{min}$ (range $33.0-159 \mathrm{~mL} / \mathrm{min}$ ). The median interval from surgery to initiation of S-1 administration was 43 days (range 12-122 days). Most patients (99\%) had a good performance status such as 0 or 1 . In total, 148 patients $(49 \%)$ underwent total gastrectomy and 156 patients $(51 \%)$ underwent partial gastrectomy.

\section{Treatment exposure}

The median treatment period for S-1 monotherapy was 324 days (range 12-408 days). Dose reduction at the initiation of S-1 monotherapy was performed in 34 patients. The leading reason for dose reduction at the initiation of S-1 monotherapy was advanced age in 12 patients $(35.3 \%)$. Other causes were low creatinine clearance in nine patients $(26.5 \%)$, poor nutrition in six patients $(17.6 \%)$, organ dysfunction in five patients $(14.7 \%)$, and history of cardiac disease in two patients $(5.9 \%)$. Dose reduction during S-1 monotherapy was required 222 times
Table 1 Patient characteristics

\begin{tabular}{ll}
\hline Age (years) & $67(30-83)$ \\
Median (range) & \\
Sex & $211(69.4 \%)$ \\
Male & $93(30.6 \%)$ \\
Female & \\
Creatinine clearance ${ }^{\mathrm{a}}(\mathrm{mL} / \mathrm{min})$ & $78.2(33.0-159)$ \\
$\quad$ Median (range) & $43(12-122)$ \\
Time from surgery to start of S-1 administration $($ days $)$ \\
$\quad$ Median (range) \\
ECOG PS \\
0 & $166(54.6 \%)$ \\
1 & $135(44.4 \%)$ \\
2 & $3(1 \%)$ \\
Extent of gastric surgery & $148(48.7 \%)$ \\
Total gastrectomy & $156(51.3 \%)$ \\
Partial gastrectomy &
\end{tabular}

ECOG Eastern Cooperative Oncology Group, PS performance status

${ }^{a}$ Calculated by the Cockcroft-Gault equation

$(n=109)$. The leading reason for dose reduction during S-1 monotherapy was anorexia, which occurred 49 times $(22.1 \%, n=46)$, followed by diarrhea (48 times, $21.6 \%$, $n=44$ ), watering eyes (25 times, $11.3 \%, n=23$ ), fatigue (21 times, $9.5 \%, n=17$ ), oral mucositis (21 times, $9.5 \%$, $n=17)$, and rash (19 times, $8.6 \%, n=14)$. S-1 monotherapy was discontinued because of watering eyes in three patients $(0.9 \%)$ before the completion of the planned eight courses ( 1 year after surgery). The median dose intensity was $75.1 \%$ (range $45.8-100 \%$ ).

\section{Watering eyes and other adverse events}

The adverse events are shown in Table 2. Grade 2 or 3 watering eyes were observed in 77 patients $(25.3 \%)$. Of these, 72 experienced grade 2 watering eyes at onset, whereas watering eyes were not identified until the condition progressed to grade 3 in five patients. The frequency of other nonhematological adverse events ranged from 16.1 to $54.9 \%$. Watering eyes were the most frequent grade 3 nonhematological adverse event.

Figure 1 shows the cumulative frequency of grade 2 and grade 3 watering eyes during the treatment period. The median time to onset of grade 2 and grade 3 watering eyes was 82 days (range 6-344 days) and 249 days (range 84-653 days), respectively, and watering eyes were observed during the first course of S-1 monotherapy in 19 patients. The median cumulative dose at the onset of grade 2 and grade 3 watering eyes was $4174 \mathrm{mg} / \mathrm{m}^{2}$ (range $491-16,095 \mathrm{mg} / \mathrm{m}^{2}$ ) and $10,243 \mathrm{mg} / \mathrm{m}^{2} \quad$ (range $4943-16,341 \mathrm{mg} / \mathrm{m}^{2}$ ), respectively. 
Table 2 Adverse events

\begin{tabular}{llllll}
\hline & Grade 1 & Grade 2 & Grade 3 & Grade 4 & All grades \\
\hline Leukopenia & 56 & 79 & 3 & 1 & $139(45.7 \%)$ \\
Anemia & 166 & 101 & 3 & 1 & $271(89.1 \%)$ \\
Thrombocytopenia & 85 & 14 & 2 & 1 & $102(33.5 \%)$ \\
Watering eyes & $\mathrm{NA}$ & 41 & 36 & - & $77(25.3 \%)$ \\
Nausea & 71 & 26 & 2 & - & $99(32.6 \%)$ \\
Fatigue & 64 & 37 & 4 & - & $105(34.5 \%)$ \\
Anorexia & 93 & 65 & 9 & 0 & $167(54.9 \%)$ \\
Diarrhea & 88 & 56 & 4 & 0 & $148(48.7 \%)$ \\
Oral mucositis & 78 & 27 & 1 & 0 & $106(34.9 \%)$ \\
Skin hyperpigmentation & 80 & 12 & - & - & $92(29.4 \%)$ \\
Dysgeusia & 58 & 6 & - & - & $64(20.4 \%)$ \\
Rash & 31 & 16 & 2 & 0 & $49(16.1 \%)$ \\
\hline
\end{tabular}

NA not accumulated

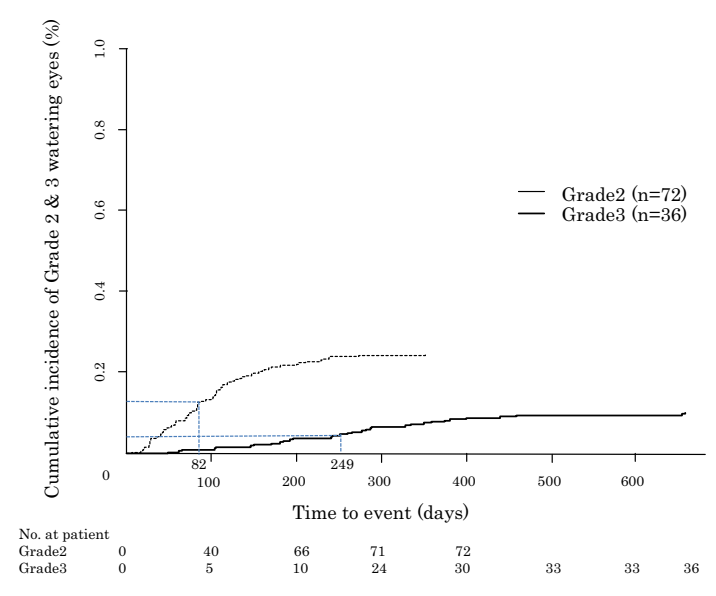

Fig. 1 The median time to the onset of grade 2 and grade 3 watering eyes was 82 and 249 days, respectively

No statistically significant relationship was found between patient characteristics and watering eyes (Table 3).

\section{Univariate and multivariate analyses of other nonhematological adverse events to predict the development of watering eyes}

The nonhematological adverse events observed during the first course of S-1 therapy are summarized in Table 4. Univariate analysis demonstrated that anorexia, oral mucositis, skin hyperpigmentation, and rash were significantly associated with the occurrence of watering eyes. In multivariate analysis, anorexia (odds ratio 2.37, $P=0.008$ ), oral mucositis (odds ratio $3.86, P=0.0003$ ), skin hyperpigmentation (odds ratio $3.84, P=0.0001$ ), and rash (odds ratio 3.76, $P=0.01$ ) showed a significant relationship with watering eyes (Table 5).

\section{Number of risk factors and probability of watering eyes}

Among the 162 patients who experienced no anorexia, oral mucositis, skin pigmentation, or rash during the first course of S-1 therapy, 19 patients $(11.7 \%)$ had watering eyes during the whole treatment course, and 37 (34.6\%) of the 107 patients experiencing one of these four adverse events and $19(59.4 \%)$ of the 32 patients experiencing two adverse events had watering eyes. No patients experienced three or four of these adverse events during the first course of S-1 therapy.

\section{The clinical course of watering eyes}

The clinical course of watering eyes is shown in Fig. 2. Of the 72 patients with grade 2 watering eyes at onset, three patients were lost to follow-up because they transferred to other hospitals after completion of S-1 monotherapy. Watering eyes disappeared completely before the completion of S-1 monotherapy in ten patients who were treated with only eye drops. In the remaining 59 patients, there was abatement of watering eyes in 28 patients after the completion of S-1 monotherapy, and worsening from grade 2 to grade 3 with a median worsening time of 162 days (range $56-533$ days) in 31 patients.

Of the 36 patients with grade 3 as the severest grade of watering eyes, including the five patients who experienced grade 3 watering eyes at onset, one patient refused stent insertion for lacrimal drainage (surgical management). Of the remaining 35 patients who received a stent for lacrimal drainage, the stent could not be placed in five patients because of strong lacrimal drainage obstruction. After stent insertion for lacrimal drainage in 30 patients, there was abatement of watering eyes in 22 patients. The median 
Table 3 Patient characteristics and watering eyes

\begin{tabular}{|c|c|c|c|}
\hline & Patients with watering eyes & Patients without watering eyes & $P$ \\
\hline \multicolumn{4}{|l|}{ Age (years) } \\
\hline$<70$ & 46 & 142 & \multirow[t]{2}{*}{0.66} \\
\hline$\geqq 70$ & 31 & 85 & \\
\hline \multicolumn{4}{|l|}{ Sex } \\
\hline Male & 56 & 155 & \multirow[t]{2}{*}{0.46} \\
\hline Female & 21 & 72 & \\
\hline \multicolumn{4}{|c|}{ Creatinine clearance $^{\mathrm{a}}(\mathrm{mL} / \mathrm{min})$} \\
\hline$<60$ & 17 & 38 & \multirow[t]{2}{*}{0.29} \\
\hline$\geqq 60$ & 60 & 189 & \\
\hline \multicolumn{4}{|c|}{ Time from surgery to start of S-1 administration (days) } \\
\hline$<43$ & 33 & 117 & \multirow[t]{2}{*}{0.18} \\
\hline$\geqq 43$ & 44 & 110 & \\
\hline \multicolumn{4}{|c|}{ Extent of gastric surgery } \\
\hline Total gastrectomy & 35 & 113 & \multirow[t]{2}{*}{0.51} \\
\hline Partial gastrectomy & 42 & 114 & \\
\hline
\end{tabular}

${ }^{\text {a }}$ Calculated by the Cockcroft-Gault equation
Table 4 Adverse events until the end of the first course of S-1 therapy

\begin{tabular}{lcc}
\hline & All grades & Grade 3 \\
\hline Nausea & 13 & 8 \\
Fatigue & 10 & 4 \\
Anorexia & 25 & 11 \\
Diarrhea & 28 & 14 \\
Oral mucositis & 22 & 11 \\
Skin hyperpigmentation & 22 & 9 \\
Dysgeusia & 4 & 2 \\
Rash & 12 & 6 \\
\hline
\end{tabular}

duration of grade 3 watering eyes was 1087 days (range 639-1830 days) in the eight patients in whom there was no abatement of watering eyes.

\section{Discussion}

Since S-1 is widely used in clinical practice, especially for adjuvant treatment of resected gastric cancer, watering eyes have come to be recognized as a significant clinical problem, which deteriorates quality of life. The incidence of watering eyes was $16 \%$ in a phase III trial conducted in Japan for metastatic AGC which involved S-1 monotherapy [2]. There have been some reports [8-15] focusing on watering eyes; however, these studies included a small number of patients and S-1 combination chemotherapy in a palliative setting, and the contribution of the ophthalmologists was not clear. This study included more than 300 AGC patients treated with adjuvant S-1 monotherapy. Although this is a retrospective study, it is considered that evaluation and treatment of watering eyes were homogeneous because one ophthalmologist managed all patients. Grade 2 or 3 watering eyes were observed in $25.3 \%$ of

Table 5 Univariate and multivariate analyses of predictive factors for watering eyes

\begin{tabular}{|c|c|c|c|c|c|c|}
\hline & \multicolumn{3}{|l|}{ Univariate analysis } & \multicolumn{3}{|c|}{ Multivariate analysis } \\
\hline & Patients with watering eyes & Patients without watering eyes & $P$ & Odds ratio & $95 \% \mathrm{CI}$ & $P$ \\
\hline Nausea & 13 & 30 & 0.43 & & & \\
\hline Fatigue & 10 & 21 & 0.36 & & & \\
\hline Anorexia & 25 & 42 & 0.01 & 2.37 & $1.254-4.467$ & 0.008 \\
\hline Diarrhea & 28 & 56 & 0.0518 & & & \\
\hline Oral mucositis & 22 & 22 & 0.0001 & 3.86 & $1.876-7.984$ & 0.0003 \\
\hline Skin hyperpigmentation & 22 & 27 & 0.001 & 3.84 & $1.945-7.611$ & 0.0001 \\
\hline Dysgeusia & 4 & 11 & 0.9 & & & \\
\hline Rash & 12 & 8 & 0.0007 & 3.76 & $1.378-10.65$ & 0.01 \\
\hline
\end{tabular}

CI confidence interval 


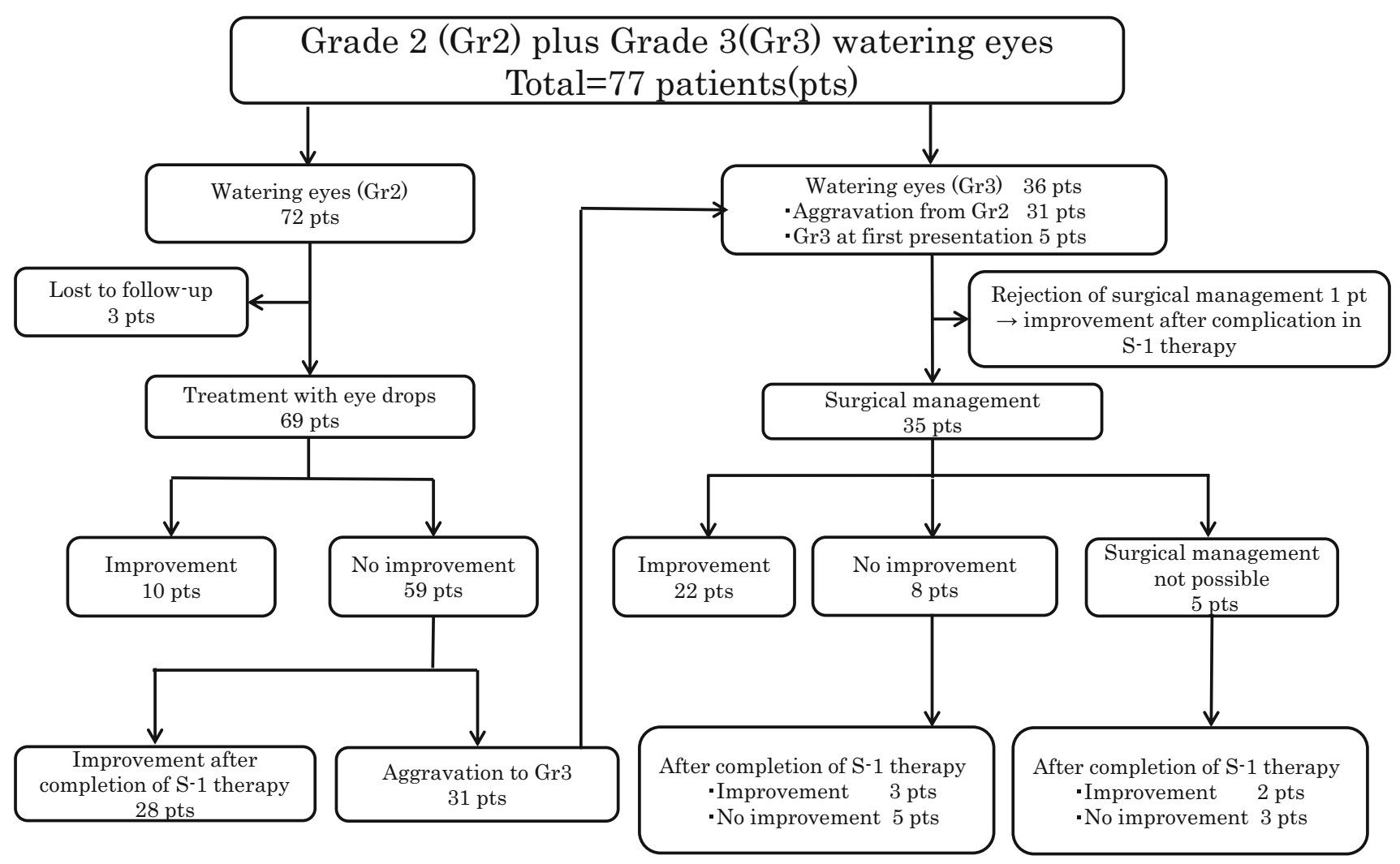

Fig. 2 The clinical course of 77 patients with watering eyes of grade 2 or 3 during the S-1 treatment

these patients. Thus, watering eyes are a common adverse event for S-1 therapy.

This is the first report focusing on the onset and clinical course of watering eyes. We found that the median time to onset was 82 days for grade 2 watering eyes and 249 days for grade 3 watering eyes. The severity of watering eyes worsened gradually from grade 2 to grade 3 in 31 of 36 patients with grade 3 watering eyes as the severest grade. Although the occurrence of grade 2 watering eyes reached a plateau after about 6 months, the occurrence of grade 3 watering eyes increased thereafter. These results mean that more than $40 \%$ of grade 2 watering eyes might worsen to grade 3. Furthermore, five patients could not receive interventional treatment because of severe lacrimal drainage obstruction. In contrast, there was abatement of watering eyes in some patients who received only eye drops. Thus, watering eyes are a late adverse event that may worsen during the treatment course if they are not treated. Because grade 1 watering eyes are difficult to detect, it is recommended that physicians should pay attention to watering eyes and administer some treatment immediately after the onset of grade 2 watering eyes to prevent worsening to grade 3 .

However, because the incidence of watering eyes $(25.3 \%)$ was not so high, regular examination of all patients who receive S-1 adjuvant chemotherapy or S-1 combination therapy by ophthalmologists is unrealistic. Therefore, risk factors for watering eyes should be recognized by physicians for early detection. In this study, although a significant relationship between patient characteristics and the occurrence of watering eyes was not found, multivariate analysis showed that anorexia, oral mucositis, skin hyperpigmentation, and rash observed during the first course of S-1 therapy were independent risk factors for watering eyes associated with high odds ratios. Moreover, the proportion of watering eyes increased with the number of these four adverse events. It is suggested that physicians consider examination of watering eyes according to the adverse events observed during the first course of S-1 therapy.

Although this study did not clarify the precise mechanism of development of watering eyes during S-1 monotherapy, a previous report [16] suggested that watering eyes during S-1 monotherapy were due to lacrimal drainage obstruction. Kitamura et al. [11] reported that a stent inserted for lacrimal drainage resulted in abatement of watering eyes caused by S-1 monotherapy. Sasaki et al. [15] reported that dacryoendoscopic observation was effective for identification of lacrimal drainage obstruction. Effective treatment of watering eyes has not been 
established. In this study, ophthalmologic intervention such as insertion of a stent for lacrimal drainage was performed in 35 patients with grade 3 watering eyes. Insertion of a stent for lacrimal drainage was effective in 22 of 35 patients $(62.9 \%)$, and there was abatement of watering eyes. Stent insertion for lacrimal drainage appears to be an effective treatment option if it is performed before severe lacrimal drainage obstruction. However, only a few ophthalmologists can perform this procedure. Furthermore, watering eyes persisted for a median duration longer than 3 years in eight patients, and in five of 13 patients with grade 3 watering eyes there was abatement after completion of S-1 monotherapy. It should be recognized that severe watering eyes may be irreversible in some patients for a long time. Reports $[11,17,18]$ have suggested the importance of early detection as well as the prediction, prophylaxis, and early treatment of watering eyes caused by $\mathrm{S}-1$. Because there is no established prophylactic treatment for watering eyes, early identification of patients at high risk of watering eyes is important in present clinical practice. Studies for prevention of watering eyes and elucidation of the underlying cause are warranted.

This study has several limitations. First, patients who discontinued S-1 monotherapy because of recurrence $(n=35)$ and adverse events other than watering eyes $(n=31)$ were excluded from this study. This exclusion which means this study was not conducted on an intentionto-treat basis might cause selection bias. Actually, the incidences of adverse events (Table 2) were relatively lower than those in previous reports. However, in contrast, including such patients, who should be censored when one is calculating the occurrence of watering eyes by KaplanMeier methods, would lead to overestimation of the occurrence of watering eyes and cause another bias. Because the patients whose treatment was discontinued because of watering eyes were included in this study, we believe this method could reduce the selection bias to assess the risk factors for watering eyes. Second, prediction could make no sense for 17 patients who developed watering eyes during the first course of S-1 therapy. Because many of these 17 patients had other adverse events (data not shown) during the first course of S-1 therapy, other adverse events observed in the first course of S-1 therapy were associated with watering eyes. Third, reevaluation of grade 2 or 3 watering eyes by an ophthalmologist might be exaggeration, and surgical intervention might be overtreatment because grade 3 watering eyes recovered without intervention in some patients. However, because each physician did not consult the ophthalmologist until development of grade 2 or 3 watering eyes, this means that patients with grade 2 or 3 watering eyes were evaluated by each physician on the basis of the patient's complaints in daily practice. Although grade 3 watering eyes were defined as "requiring surgical management such as lacrimal drainage" in CTCAE version 1.1, the indication for surgical management is not established and it is determined by an ophthalmologist after consultation with each physician. Once severe watering eyes occurred, they persisted for a long time even after completion of adjuvant chemotherapy with S-1 in some patients. The indication for surgical intervention for treatment of watering eyes, which means a detailed definition of grade 3 watering eyes, should be established as soon as possible.

In conclusion, the risk of watering eyes was higher in patients who also had anorexia, oral mucositis, skin hyperpigmentation, or rash during the first course of S-1 monotherapy than in those without them.

\section{Compliance with ethical standards}

Conflict of interest The authors declare that they have no conflict of interest.

Ethical approval Informed consent for adjuvant chemotherapy with S-1 was obtained from all patients. This study was approved by the Institutional Review Board of Shizuoka Cancer Center.

\section{References}

1. Bita E, Dominick G, Linda L, et al. Canalicular and nasolacrimal duct blockage: anocular side effect associated with the antineoplastic drug S-1. Am J Ophtalmol. 2005;140:325-7.

2. Koizumi W, Narahara H, Hara T, et al. S-1 plus cisplatin versus S-1 alone for first-line treatment of advanced gastric cancer (SPIRITS trial): a phase III trial. Lancet Oncol. 2007;9:215-21.

3. Narahara $H$, Iishi $H$, Imamura $H$, et al. Randomized phase III study comparing the efficacy and safety of irinotecan plus S-1 with S-1 alone as first-line treatment for advanced gastric cancer (study GC0301/TOP-002). Gastric Cancer. 2011;14:72-80.

4. Boku N, Yamamoto S, Fukuda H, et al. Fluorouracil versus combination of irinotecan plus cisplatin versus S-1 in metastatic gastric cancer: a randomised phase 3 study. Lancet Oncol. 2009;10:1063-9.

5. Sakuramoto S, Sasako M, Yamaguchi T, et al. Adjuvant chemotherapy for gastric cancer with $\mathrm{S}-1$, an oral fluoropyrimidine. N Engl J Med. 2007;357:1810-20.

6. Kanazawa T, Tanakaya K, Takeuchi $\mathrm{H}$, et al. Two cases of lacrimal duct occlusion caused by S-1 therapy in patients with gastrointestinal cancer. J Jpn Coll Surg. 2008;33:150-4.

7. Prasad S, Kamath GG, Phillips RP. Lacrimal canalicular stenosis associated with systemic 5-fluorouacil therapy. Acta Ophthalmol Scand. 2000;78:110-3.

8. Eiseman AS, Flanagan JC, Brooks AB, et al. Ocular surface, ocular adnexal, and lacrimal complications associated with the use of systemic 5-fluorouracil. Ophthal Plast Reconstr Surg. 2003;19:216-24.

9. Kim N, Park C, Park DJ, et al. Lacrimal drainage obstruction in gastric cancer patients receiving S-1 chemotherapy. Ann Oncol. 2012;23:2065-71.

10. Park J-S, Ha SW, Lew H. Two cases of lacrimal drainage obstruction associated with S-1 anticancer treatment. J Korean Ophthalmol Soc. 2010;51:890-4.

11. Kitamura H, Miyanaga $\mathrm{T}$, Shin $\mathrm{H}$, et al. Investigation of epiphora following S-1 therapy. Jpn J Cancer Chemother. 2011;38:259-62. 
12. Shioda K, Tanabe K, Kimura S, et al. Treatment of severe canalicular blockage secondary to peroral TS-1. Jan J Clin Ophthalmol. 2009;63:1499-502.

13. Kashiwagi H. Ocular disorders of anticancer drugs-ocular side effects. Jpn J Cancer Chemother. 2010;37:1639-44.

14. Sakai J, Inoue $Y$, Kashiwagi $H$, et al. Multi-institutional survey on the lacrimal side effects of TS-1. Jan J Clin Ophthalmol. 2012;66:271-4.

15. Sasaki T, Miyashita H, Miyanaga T, et al. Dacryoendoscopic observation and incidence of canalicular obstruction/stenosis associated with S-1, an oral anticancerdrug. Jpn J Ophthalmol. 2012;56:214-8.
16. Ito S, Tanaka A. Three cases of corneal disorders associated with an oral anticancer drug S-1. Nippon Ganka Gakkai Zasshi. 2006;110:919-23.

17. Shibahara H, Kuze $\mathrm{S}$, Kyokane T, et al. Optic lesions in patients with epiphora during S-1 therapy. Jpn J Cancer Chemother. 2010;37:1735-9.

18. Kashiwagi H. Lacrimal drainage obstruction and stenosis associated with anti-cancer drug S-1. J Eye. 2013;30:915-21. 